\title{
Assessing the Arabic Translation of Selected Walt Disney Bedtime Stories (2014): A Pragma-Stylistic Approach
}

\author{
By: Monica Mouris Naguib \\ Under the supervision of \\ Prof. Nahwat El-Arousy \& Prof. Mona Fouad Attia
}

\section{Abstract}

Every translation process should be guided by "a communicative purpose of the source text which is supposed to be fulfilled in the target text" (Nord, 2006, p.44). This paper seeks to examine the role of the pragmatic analysis in assessing the quality of the translation process by formulating a tripartite model. This model combines the pragmatic analysis and two functional translation models, which are Nord (1997) and House (2015) to tackle the translation quality assessment. Specifically, this paper assesses the Arabic translation of one bedtime short stories selected from children's Disney book, 365 Bedtime Stories (2014). The researcher applies a pragma-stylistic framework along with two functional translation models to measure the quality assessment of the target texts and minimize the gap between the two cultures in the source and the target texts of children's literature. Consequently, the study provides further suggestions for the translation gaps and errors which are found in the translated target texts by applying Baker's (2011) and Van Coillie's (2006) strategies. This paper tests the validity of the proposed model to perform a pragma-stylistic model that helps in the translation quality assessment to classify the translation errors and offer solutions that can be used in any children's literature.

Keywords: Translation quality assessment (TQA), pragmatics, functional translation theories, register analysis, children's literature 


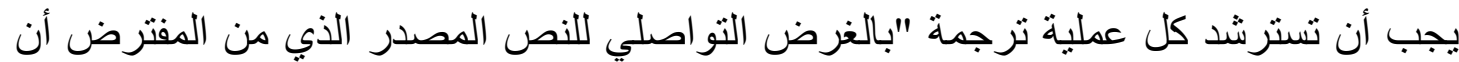

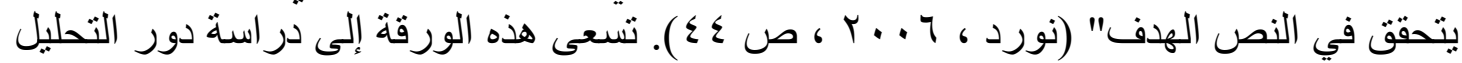

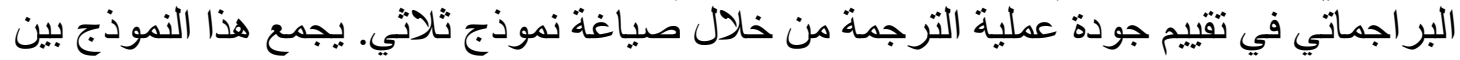

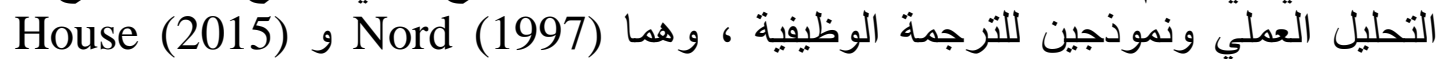

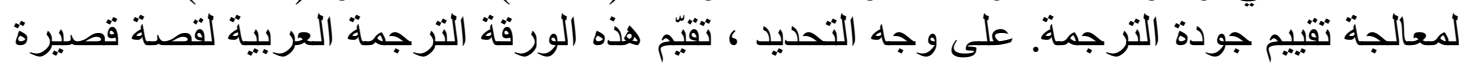

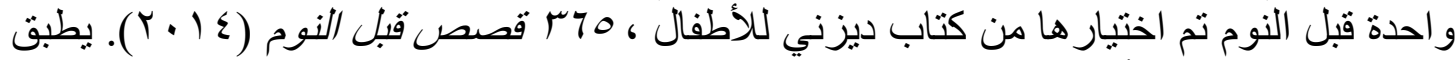

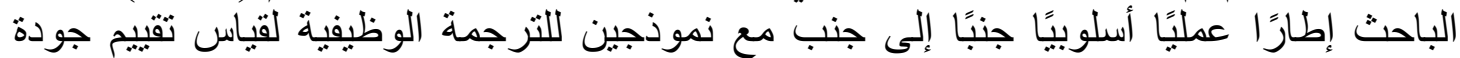

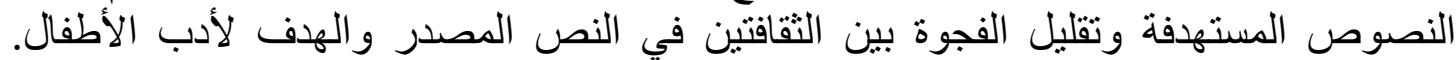

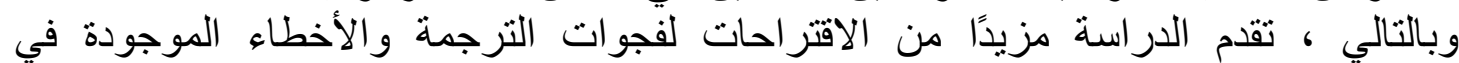

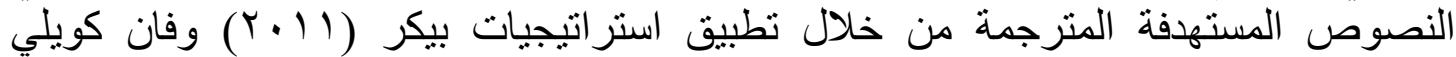

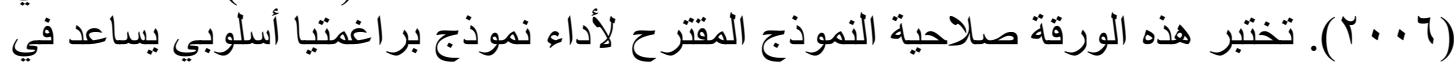

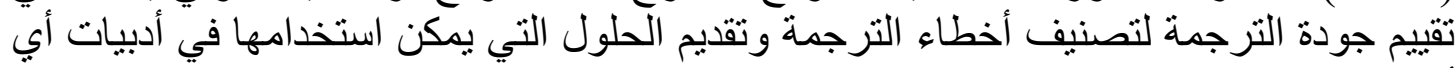
أطفال.

الكلمات المفتاحية: تقييم جودة الترجمة (TQA) ، البر اغماتية ، نظريات الترجمة الوظيفية ، تحليل التسجيل ، أدب الأطفال تهئ 
Monica Mouris Naguib

\title{
Assessing the Arabic Translation of Selected Walt Disney Bedtime Stories (2014): A Pragma-Stylistic Approach
}

\author{
By: Monica Mouris Naguib \\ Under the supervision of \\ Prof. Nahwat El-Arousy \& Prof. Mona Fouad Attia
}

\section{Introduction}

Literature is considered as a mirror of society's culture and a powerful medium that allows people to better understand the world they live in (Xeni, 2007). There has been a shift to grab attention to the genre of children's literature in the mid-nineteenth century. Recently, children's literature is considered potentially rich data to be analyzed by linguists, where there is specific attention to children's literature translation. A linguistic approach to children's literature enables researchers to analyze accomplished works. The translator as a powerful mediator should consider all aspects of translation when dealing with children's literature. Lathey (2006) argues that although the translator's name does not appear in the text, his voice is marked in the text by his/her discursive presence. This study aims to be beneficial to the efforts of the linguistic scholars, translators, or any other parties which are interested in assessing children's literature.

The context of the present study integrates the fields of linguistics and translation. It revolves around the analysis and the translation quality assessment of selected story from a recent published Disney children book named "365 Bedtime Stories" and its translated version " "قبل النوم". In this paper, the researcher applies two functional approaches in assessing the translation quality which are Nord's (1997) translationoriented text analysis and House's (2015) translation quality assessment model. They are used to assess the translation quality and to trigger the translation pitfalls. Then, Baker's (2011) and van Coillie's (2006) strategies are assigned to propose solutions for the detected translation pitfalls in the analyzed stories. Here, Stylistics means the style which facilitates analyzing and identifying the important aspects of texts in a certain way (Farghal \& Almanna, 2015, p.141).

Therefore, this paper aims to evaluate the performance of a proposed model to assess the translation quality of selected children's bedtime stories to be used by analysts. The present paper aims at proposing a model for analyzing texts by applying a pragma-stylistic framework to improve the quality of the translated TTs to be able to identify the 
translation pitfalls. Thus, the purpose of this paper is to present a pragmatic analysis for the selected data to reveal the author's intended messages and intentions in the STs, and to assess the translation of the stories TTs by applying functional TQA models.

Hence, the current paper aims at achieving three main objectives, which are listed as follows:

1. Analyze the STs by applying a pragma-stylistic analysis to reveal the author's intended meanings and intentions.

2. Detect how the translators transfer the STs on the pragmatic level into the TTs.

3. Test the validity of the presented TQA model to assess the quality of translation for children's literature.

Based on the above objectives and to reach the mentioned purpose, the current paper is designed to answer the following questions:

1- How can the pragma-stylistic analysis of the selected data uncover the author'sintended messages?

2- How far does the pragmatic analysis help the scholars of translation to assess the translation of children's literature?

3- To what extent is the proposed model capable of assessing the translation quality of the TTs, detecting the translation errors, and presenting further suggestions?

The significance of this paper lies in its attempt to emphasize the essential role of the pragmatic analysis in assessing and simplifying the translation process of children's literature in a proposed model. What makes this paper different from any other pragmatically orientated studies is that it tends to frame a model for analyzing children's literature, which could serve as a comprehensive model that provides the analysts with the tools needed to assess such genre.

\section{Pragmatics}

There are too many definitions, and points of view for the concept of pragmatics which are raised by linguists and scholars, who are interested in the field. One of the pioneers and leading figures in modern linguistics, Mey (1993) points out that research in pragmatics deals with how language speakers interact in various situations and contexts. From his point of view, the actual focus of pragmatics is to know how participants communicate in a context. It is commonly assumed that different contexts imply different meanings and effects which could be a critical issue in translation. 


\section{Monica Mouris Naguib}

Several linguists (Almanna, 2016; Emery, 2004; Farghal, 2012; Hall, 2008; House, 2015; Lahlali \& Hatab, 2014; Leech, 1983; Levinson, 1983; Newbert, 1985; Newmark, 1981) believe in the importance of the pragmatic dimension in the communicative situation, to interpret the message within a context. In her definition of pragmatics, Baker (2011) asserts that meaning is not "generated by the linguistic system, but as conveyed and manipulated by participants in a communicative situation" (p.27). In other words, pragmatics is concerned with the study of language in context. It is the meaning as communicated by a speaker or a writer and interpreted by a listener or a reader (Yule, 1996a). Yule (1996a) summarizes the definitions that highlight the nature of pragmatics as" (a) the study of speaker meaning, (b) the study of Contextual meaning, (c) the study of how more gets communicated than is said, and (d) the study of the expression of relative distance" (p.3). Here is a short brief on the pragmatic aspects that are used in the analysis.

\subsection{Presupposition}

Many linguists attempt to explain and define the term presupposition from several perspectives. Green's (1996) confirms the idea of the speakers' belief that the meaning of a 'presupposition construction is noncontroversial, even if it is controversial and is not taken for granted by the receiver" (p.65). In other words, presupposition is related to linguistic and extra-linguistic knowledge the sender assumes the receiver must understand the whole message. According to Crystal (2008), presupposition is "what the speaker assumes in saying a particular sentence, as opposed to what is asserted" (p.384).

Any sentence can be regarded as a potential presupposition that can be changed into an actual presupposition by the speaker's use in a certain context. Accordingly, Yule (1996b, pp. 27-30) presents different types of presupposition and their triggers, which are used in the analysis of speakers' utterances. These types are existential presupposition, factive presupposition, lexical presupposition, structural presupposition, nonfactive presupposition, and counter-factual presupposition.

In general, presuppositions are problematic in different languages and contexts, especially in the translation process. This occurs when the TR is not fully aware of the source's cultural aspects, which are presented in the ST and transferred into the TT. It is commonly assumed that the reason for this is because the ST is translated after a long time, so the original information is no longer triggered by a reference, or the translator misinterprets the underlined presupposition of the ST (Yule, 1996b). Thus, Nord (1991/2005) suggests that the translator should "adjust the 
level of explicitness to the [assumed] general background knowledge of the intended TT recipient" (p.98).

\subsection{Speech Act Theory}

The term Speech Act does not refer simply to the act of speaking, but to the whole communicative process, which includes the context of the utterance, the involved participants in the situation, and any paralinguistic features which may contribute to the meaning of the interaction (Black, 2006). Similarly, Crystal (2008) defines speech act as "a communicative activity [Locutionary act], defined with the intentions of speakers while speaking [Illocutionary force] and the effects they achieve on listeners [Perlocutionary effect]" (p.446). Thus, speech act theory focuses on the importance of linking the illocutionary force or the communicative force tothe perlocutionary effect of the utterances.

According to Austin (1962), a speech act is what is said by an individual that not only presents his/her speech but also performs an action. He discusses the meaning of utterances that have the kind of performative functions by defining speech acts as "actions performed via utterances" and defines the speech event "as the circumstances surrounding the utterance" (p.6). Therefore, speech act theory helps in explaining how people do things with words and what happens when things are misinterpreted. These acts are defined as follows:

a. Locutionary act refers to the exact meaning of the words used in the utterance.

b. Illocutionary act refers to the communicative force of the utterance.

c. Perlocutionary act refers to the effect of the utterance on the hearer or receiver. The perlocutionary act can be (a) object perlocutionary acts, the speaker's intended meaning, or (b) sequel perlocutionary act, the unintentional result arising from the hearer's misinterpretation of the speaker's meaning (Austin, 1962, p.118).

Austin's (1962) speech act theory deals with the utterance as an act of performance by a speaker in a context with an addressee. Searle (1976) develops Austin's original work of speech act theory, as he focuses more on what the speaker does, not the hearer. However, his contribution allows us to shift our focus from the intentions of the speaker to how the hearer reaches the speaker's intention. Besides, Searle (1976) points out that "the basic unit of human linguistic communication is the illocutionary act" ( $p, 1)$, which is performed by the speaker that has a force such as promising, commanding, requesting, etc. Searle (1976) presents his taxonomy of what he regards "as the basic categories of illocutionary acts" (p.10). Black (2006) summarizes Searle's (1976) list 


\section{Monica Mouris Naguib}

of speech acts' types which are representative speech acts, expressive speech acts, directive speech acts, commissive speech acts, and declarative speech acts.

According to Searle (1969), any kind of successful conversational interaction depends on the shared linguistic and non-linguistic knowledge between the speaker and the hearer. According to him, speaking a language "is performing acts according to rules" (pp.36-37). For illustration, Searle (1976) analyzes the illocutionary act of promising. For example, he starts by describing a situation in which a speaker directs a sentence to a hearer which he promises to do. To perform a successful illocutionary act, one must follow what he calls Felicity conditions (Searle, 1976, pp.54-63), he proposes these conditions in detail for the promising act, which can be summarized as follows:

- General condition: the ability of the speaker to understand the language in use,

- Content condition: the message itself,

- Preparatory condition: as the event will not take place by itself,

- Sincerity condition: the intention of the speaker to do the act, and

- Essential condition: Utterances change the state from nonobligation to obligation.

\subsection{Cooperative Principle and Implicature}

Grice's (1975) claims that human interaction or communication is threatened to be damaged by various kinds of implicature; that is why he believes in the co-operative principle to be a guide to human communication. His entire principle depends on a fundamental premise of interaction which he refers to as the Cooperative Principle (CP). The principle states "Make your conversational contribution such as is required, at the stage at which it occurs by the accepted purpose or direction of the talk exchange in which you are engaged" (Grice, 1975, p.45). However, people do not usually follow the principle which results in generating additional conveyed meaning in their utterances. Thus, Grice (1975) defines this phenomenon as implicature which explains how speakers use indirectness as a strategy in conversations to imply further meanings (Brown \& Yule, 1983; Neale, 1992; as cited in Carston, 2002). Additionally, Baker (2011) defines implicature as "what the speaker means or implies rather than what is said" (p.223).

Participants involved in a conversation are assumed to be following these maxims to fulfill the cooperative purpose. These maxims are listed as follows:

1. Maxim of Quality: make your contribution one that is true and do not say what you believe to be false, and do not say that for 
which you lack adequate evidence.

2. Maxim of Quantity: make your contribution as informative as required for the current purposes of the exchange, and do not make your contribution more / less informative than is required.

3. Maxim of Relation: say things that are relevant to the context.

4. Maxim of Manner: avoid obscurity of expression, be brief, be orderly, and avoid ambiguity. (Grice, 1975, p.45)

Nevertheless, on many occasions, speakers may choose not to follow these maxims for a communicative purpose to generate indirect messages (Grice, 1975). This obvious deviation can take place in different forms of non-observance such as violation, flouting, infringing, opting out, or suspending. Thus, he distinguishes between two types of implicature, namely conversational implicature, and conventional implicature. Both convey an additional level of meaning beyond their surface meaning.

Grice (1975) points out that the conversational implicature is "essentially connected with certain general features of discourse" (p.45). Conversational Implicature derives from the general principle of conversation and the maxims, depending on the cooperative principle that speakers will normally obey (Brown \& Yule, 1983). It focuses on the ability of speakers to diverge from conventionality and still create implicatures. Correspondingly, Grice (1975) differentiates between two types of conversational implicature which are generalized conversational implicature and particularized conversational implicature. Both types are related to the absence or the presence of the context of the utterance: First, a generalized implicature arises in cases in which "one can say that the use of a certain form of words in an utterance would normally carry such-and-such an implicature or type of implicature" (Grice, 1989, p.37). In other words, generalized conversational implicatures arise unrelatedly to the context in which the utterance occurs. On the other hand, conventional implicature is the second type of implicatures; it arises from the combination of language and context; in other words, the same utterance on different occasions might not generate the same implicature.

\subsection{Politeness theory}

Different definitions of politeness are presented by many scholars. Lakoff (1990) defines it as "a system of interpersonal relations designed to facilitate interaction by minimizing the potential for conflict and confrontation inherent in all human interchange" (p.34). Simply, politeness is the most "prominent motivation for indirectness in requests and certain forms naturally tend to become the conventionally polite ways of making indirect utterances" (Senft, 2014, p. 28). Moreover, Leech (1983) summarizes the function of the politeness principle as "to maintain 


\section{Monica Mouris Naguib}

the social equilibrium and the friendly relations which enable us to assume that our interlocutors are being cooperative in the first place" (p.82). Later, Crystal (2008) asserts this notion in his definition as follows "politeness is a term which characterizes linguistic features mediating norms of social behavior" (p.373).

The formal linguistic model of politeness is put forward by Brown and Levinson (1983) as they maintain the concept of face. They introduce strategies to minimize threats and to accomplish linguistic politeness. In this sense, politeness can be defined as a means used by the participants to express their awareness of the other's faces (Yule, 1996a, p.60). The first strategy introduced by Brown and Levinson (1987) is on record. This strategy is commonly used in environments where the relationship between the addresser and the addressee is like the relation between family members, or close friends. On the contrary, an off-record (indirect) strategy occurs when the addresser tries to avoid any imposition by using all kinds of hints to communicate or not to state the meaning directly. It occurs throughout (a) giving hints, (b) being vague, and (c) being sarcastic or joking.

It is essential to consider the nature of the relationship between the addresser and the addressee; otherwise one may think that there is an embarrassment or some sort of displeasing for the addressee. From a pragmatic perspective, the third strategy is baldly (without redress), where the speakers are involved to communicate in a very direct and clear way; in other words, it has to follow Grice's (1967) cooperative principle and maxims within the interaction. Another strategy is redressive actions; they are actions that save the face of the addressees to overcome the potential face damage of the FTA (Brown \& Levinson, 1987).

Scollon and Scollon (2001) propose a model of social interaction to analyze the negotiation of face relationships in intercultural communication. They aim to discover the whole communication system of which politeness is a part, as they outline the characteristic of three types of systems which are solidarity politeness system, deference politeness system, and hierarchical politeness system. The politeness systems are designed on the power difference $(+\mathrm{P}$ or $-\mathrm{P})$ and the distance between participants $(+\mathrm{D}$ or $-\mathrm{D})$. This kind of system favors the deference, indirectness, or even avoidance of making impositions on others at all (Pan, 2006). In the solidarity politeness system, participants see themselves as equal in social class and relations in a group, while in the hierarchical politeness system, the participants respect the social differences that place the speaker in a superordinate position on the hearer (Scollon \& Scollon, 2001, p. 45). 


\section{Translation Quality Assessment Models}

Throughout the history of language, scholars have approached the discipline of translation studies from various perspectives. Supporting the rationale of the current paper, translation has played a critical role in creating a world of literature for children from different cultures. Recently, some scholars have given special attention to this genre of literature in translation by presenting strategies such as Lathey (2010), Oittinen (2000), and Zohar (1986). However, one dilemma that has continued over the years is the decision on the best method or strategy to be followed in the translation process.

Accordingly, what is important is to focus on the relationship between the source text and the translated text to measure and express the quality of translation. It is a type of evaluation as described by Scriven (2007; as cited in Williams, 2009). Since texts may consist of verbal and nonverbal signs, their usage in a particular text may be governed by culture-specific norms and conventions. Therefore, translators bridge the gap between contexts that have not got enough common ground for the sender and receiver to communicate effectively on their own. From this point of view, translation can be regarded as "an intentional, intercultural, partly verbal communicative interaction" (Nord, 1997/2005, p.17). Thus, translators should follow a specific model to be able to assess their translation to facilitate communication between members of different cultures.

\subsection{Nord's (1997) Model: Translation Oriented Text Analysis}

One of the organized functional models of text analysis in translation is presented by Nord (1991/2005) with a qualitative nature that examines text organization on or above sentence level. Besides, it enables the researcher to compare the function of the ST features in a separate profile apart from a TT profile. Nord's (1997) approach aims to provide "criteria for the classification of texts for translation classes and some guidelines for assessing the quality of the translation" (Nord, 1991/2005, p.2). Although it aims primarily at providing the translation students with an ST analysis model, it is considered as a clue or ground for translation assessment to be more than subjective criticism only (Nord, 1991/2005). One of the beneficial aspects regarding her model is that it is not restricted to any specific text type or specific characteristics of ST. Nord (1997) differentiates between two basic types of translation processes, as a communicative interaction, which is (a) documentary translation, and (b) instrumental translation. 


\section{Monica Mouris Naguib}

Nord's (1997) modified model is a more flexible version than her model in 1991. It highlights three important aspects which are the importance of the translation commission, the role of the ST, and the functional hierarchy of translation problems. According to Nord (1991/2005; 1997), in order to help the translator to succeed in his/her choices, a translation brief should be done. Since the function of the ST may not differ from the TT function, the translation brief describes the situational factors that determine the communicative aim and the translator's needs. Thus, each translation task should be accompanied by a commission or a brief that identifies the function of the TT and its conditions (Nord, 1997).

Following Reiss and Vermeer (1984), Nord (1997) describes translation as a "new offer of information in the target culture about the information offered in the source culture and language" (p.76). This means that analyzing the ST is considered the starting point to provide information about the feasibility of assessment to determine the relevant ST units to this functional translation and which translation strategy should be followed to meet the translation brief requirements. Nord (1997) presents one possible model for ST analysis (that is used in this research) by a list of intra- textual factors.

Nord (1997) establishes a functional hierarchy when undertaking a translation which are (a) the intended function of the translation should be decided, (b) those functional elements that will need to be adapted to the TT addressees' situation have to be determined, (c) the translation type decides the translation style (whether source-culture or target cultureoriented texts), then (d) the problems of the text can then be tackled at a lower linguistic level.

What makes the model credible is that it can be used for analyzing both ST and TT. It is worth pointing out that the translator should compare the ST and TT profiles to define the aspects in which the two texts diverge. For a translator to understand certain ST in a certain SL, s/he should know the source's cultural features and find the author's communicative purposes. The translator's assessment of the communicative situation of the intended source messages is determined by the different target culture conditions in a TL. Hence, this difference is not a result of the change of the audience only (i.e. including their cultural knowledge, values systems, and ideologies), but also it may differ with regards to the extra-textual or pragmatic factors.

\subsection{House's (1997; 2015) Model: Translation Quality Assessment}

House's model (1997) also relies on the native speaker's intuition and on the judgments of other native speakers, which are taken as 
presumptions. House (1997) stresses the fact that equivalent relations between two languages are not absolute, but they fall on a scale of equivalent items that run from more to less probable. This degree of probability can only be judged by a subjective, hermeneutic element according to the native speaker's perception.

In her revised model, House (1997) uses for the analysis and the comparison of an original text (ST) and its translation (TT) Halliday's (1978) register concepts of Field, Tenor, and Mode, as well as, the genre to distinguish the variety of user (setting) and the variety of use (purpose). It helps to show the translation method employed and highlights the errors. First, field dimension is related to the topic (subject matter), content (social activity), and the subject of the text (including degrees of generality or specificity lexical items). Second, tenor refers to the nature of the relationship between the participants involved in the discourse. This relationship is tested in terms of social power, distance, and attitude. There is a difference between (a) tenor formal attitude lexis and (b) informal attitude lexis, as the first may include complete and politeness expressions and the latter may include slang and abbreviations (Muntigl \& Horvath, 2005). Third, mode is the channel and the degree of participation between the writer and the reader (House, 1977). It may be considered as House's (1977) social role relationship dimension of language use.

The exact steps for applying House's (1997) modified model are summarized in Munday (2001) as follows:

1. A profile of ST register and description of its genre is added to establish the function of the text. From the researcher's point of view, it is like Nord's (1997) translation commission.

2. This function of ST is reproduced in the translation TT.

3. A similar profile is carried out for the TT.

4. A comparison is held between the profiles of the ST and TT. This comparison creates a list of mismatches or errors that can be categorized as covert (at Register and Genre level) or overt (denotative meaning at text level) errors.

5. Final qualitative judgment. (p.93)

Moreover, House (2015) highlights the role of the category of the genre "into the analytic scheme between the register categories" (p.64). Thus, while the register is concerned with the connection of the texts and their micro-context, genre focuses on the connection of texts and their macro context of the linguistic and cultural factors. In other words, the register is the set of linguistic features while the genre is the set of determination. However, in her latest modified mode. House (2015) 


\section{Monica Mouris Naguib}

proposes her new internal workings of the dimensions of Field, Tenor, and Mode, as follows:

Thus, within Field, the analysis now focuses only on lexis, the granularity of lexis, lexical fields and Hallidayan processes (material, mental, and relational). Within Tenor, only lexical and syntactic choices are examined along with the subcategories of stance, social role relationship, social attitude, and participation. And along with Mode, the analysis will focus as before medium, theme-rheme, and connectivity (coherence and cohesion (p.126).

In this sense, House (1997) suggests that researchers should prepare separate profiles for ST and TT. When the STs and the TTs profiles do not match, then, there is an error. Briefly, covert errors are those errors that result from a mismatch of one situational dimension with a similar one in TT. While overt errors are those errors that result from a nondimensional mismatch. Overt errors are further categorized into seven subcategories which are (a) not translated items, (b) slight change in meaning, (c) significant change in meaning, (d) distortion of meaning, (e) breach of the SL system, (f) words or expressions which do not exist in the original text, and $(\mathrm{g})$ cultural filtering.

With regards to the evaluation or assessment of different translation texts of the same ST, the cultural filter reduces the difficulty of the process. This helps in dealing with the covert translation texts and the overt translation texts; the latter is more difficult. Hence, House (2015) prefers a straight foreword translation of some discourses towards the ST to find the linguistic-cultural equivalents. Consequently, the analysis used by House $(1977 ; 1997 ; 2015)$ is a qualitative and quantitative analysis, in which the latter aims at (a) verifying the results of the qualitative analysis, and (b) revealing preferred usage of forms with a certain language system.

\subsection{Baker's (2011) strategies: In Other Words}

Baker (2011) discuses some translation problems that arise from the lack of equivalence between texts on different levels such as: the word level, above the word level, grammatical equivalence, textual equivalence and pragmatic equivalence. Besides, she investigates how cohesion and coherence are critical tools in translation because of their nature and the diversity of linguistic and non-linguistic factors, which can affect the context of the TT. The choice of the suitable word equivalent will always be a struggle, as it depends only on the linguistic system or systems being handled by the translator. Hence, she presents some of the pitfalls in 
translation that face translators regarding non-equivalence which can be summarized as follows:

- Culture-specific concepts occur when the SL word reflects a concept that is unknown in the target culture.

- The SL concept is not lexicalized in the TL,

- The SL word is semantically complex,

- The SL and TL make different distinctions in meaning,

- The TL lacks a superordinate,

- Lack of a specific term (hyponym) in TL,

- Differences in physical or interpersonal perspective,

- Differences in expressive meaning,

- Differences in the form (such as certain suffixes and prefixes),

- Differences in frequency and purpose of using specific forms, or

- Usage of loan words in the ST. (Baker, 2011, pp. 21-24)

In dealing with such kind of non-equivalence; first, it is important to determine the significanceand implications of the ST, as the translator has to convey approximately the same meaning of the ST for the TT reader to fully understand the whole notion of the ST. On the other hand, Baker (2011) suggests several strategies used by professional translators to minimize the gap of equivalence between the SL and TL. Thus, these strategies may help in solving the pitfalls that occur during the translation process which are as follows:

Translation by more general word

Translation by a more neutral/less expressive word

Translation by cultural substitution

Translation using a loan word plus explanation

Translation by paraphrase using a related word

Translation by omission

Translation by illustration. (Baker, 2011, pp.26-42)

\section{4. van Coillie's (2006) strategies: Translating proper names}

Names of characters in children's literature are not selected haphazardly by the writers, but they serve specific purposes or functions (Nord, 1997). Sometimes the choice of the names delights the readers by raising certain feelings and emotions (to strengthen the expressive and appellative functions). In translation studies, from a pragmatic approach, the function of a text has been a prominent key in the analysis of discourse (House, 1997; Nord, 1997; Reiss \& Vermeer, 1984). In the same sense, van Coillie (2006) identifies six functions of language to investigate the vision of the authors and the need of the readers, which 
are (a) informative function, (b) formative function, (c) emotive function, (d) creative function, (e) divertive function, and (f) aesthetic function.

The translation of characters' names or the settings where the story is taking place is important and critical in children's literature. Some problems may appear such as the difference in intended effects (i.e. emotive function) of the SL is not shown in the TL, or it is too difficult to be read in the TL (i.e. informative function), or sometimes the connotation of the SL is not rendered in the TL (i.e. humorous effect). According to Nida (1964), the ST and TT should be considered functionally and dynamically equivalent. The decision of the translators to keep or change the original names of the ST depends on the role played by the characters' names in the whole text. Context can be used to identify the function of the name and to bridge the gap between the ST and TT (i.e. to reflect the emotional function or connotation impact). Thus, van Coillie (2006) states that "the more important the context is to the book, the less self-evident it is to change thatcontext" (p.131).

Hence, he suggests ten strategies that can be adopted by translators in translating difficult names. However, for the sake of the study's purpose, eight strategies are summarized as follows (a) non-translation, (b) non-translation plus additional explanation, (c) replacement of a personal name by a common noun, (d) replacement of the name by a counterpart in the TL, (e) replacement by a more widely known name from the SL or source culture within the same function, (f) cultural substitution, (g) replacement by another name from the TL, or (h) deletion.

In conclusion, in translating the names of the characters, translators should be aware of the cultural aspect of TR towards the ST. So, it could be easier for children to identify characters whose names sound familiar. On the other hand, the second group believes in engaging children into other cultures via translation (Pascua, 2006; as cited in van Coillie, 2006).

4. The Proposed Model

The model is a tripartite model that is conducted on three levels. First; applying a pragmatic stylistic analysis, second; applying House's (2015) register analysis to identify the language function embedded in the text regarding Nord's (1997) translation commission and third; provide solutions and suggestions. In the beginning, the story is analyzed on the pragmatic stylistic level, followed by the register analysis that is made on the ST in detail to figure out the intended function of the ST. A comparison between the ST and TT profiles is made to show the pitfalls concerning the translation brief. The last step is suggesting solutions to 
enhance the quality of the TTs. A diagram for the proposed model is introduced in Figure 4.1.

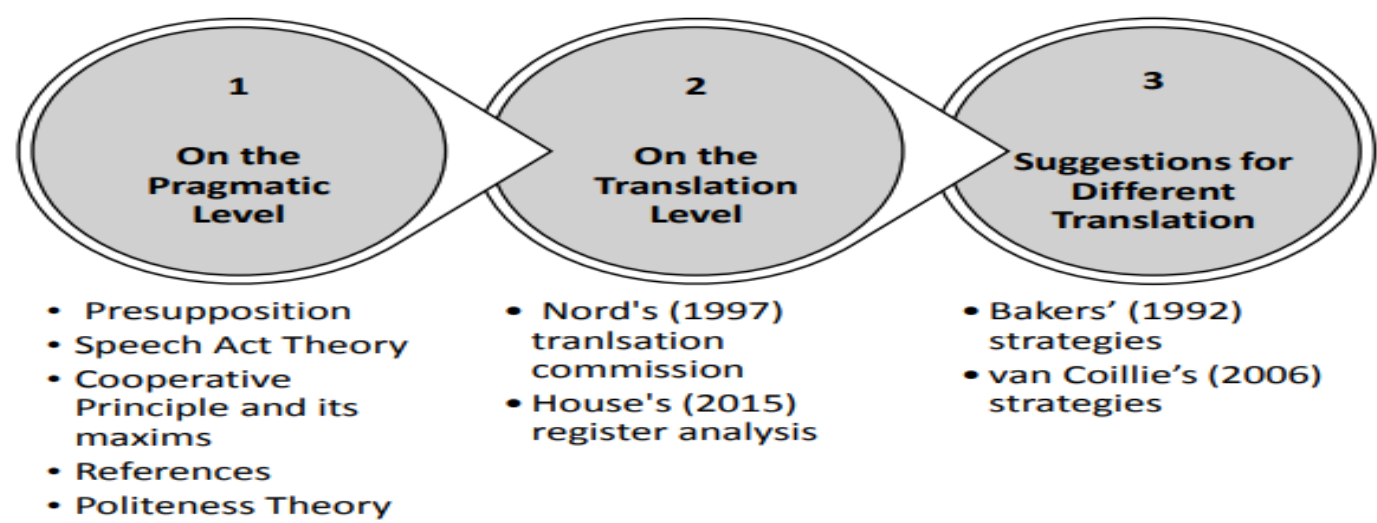

Figure 4.1. A proposed TQA Model for analyzing children's Literature

\section{Sample Analysis: Money Matters}

This short story is inspired by the Disney computer-animated film, Toy Story. In this story, Buzz discovers money, which he believes that it may influence his imaginary report to the space base on the rest of the toys. The writer intends to convey how people use money in a simple style. It all starts when Buzz notices Andy puts several round silver discs in Hamm, Andy's pig bank. First, he thinks it is a kind of energy power! But after a short conversation with Hamm and Bo-Peep, the shepherdess, Buzz knows that it is money. Then Woody, Andy's favorite toy, starts to illustrate how people use the money to buy things they need. Finally, the story ends with Buzz's utterance to the rest of the toys in which he announces being different from them. The story is analyzed on the pragmatic level for both the ST and TT, followed by a detailed application of the translation quality assessment models.

The short story entitled Money Matters implies the author's idea about how important the subject is. The verb "matter" is defined by Cambridge Dictionary as "to be important or to influence what happens". The title is stated in a simple structure similar to the SL system which is (SVO), and since 'matter' can be considered as an intransitive verb, which does not need an object, the title is accepted. The title of a story is usually used to grab attention. Here, the writer violates the maxim of quantity, as the contribution is not as informative as required. In other words, the writer does not mention in what ways money matters.

\subsection{Step 1: On Pragmatic level}

Regarding the title of the TT ( أهمية النقود), Baker (2011) mentions that differences in the structure of the ST and TT often cause a "change in the 


\section{Monica Mouris Naguib}

information content of the message" (p.95). Generally, the choice of the verb's tense and aspect usually need two key types of information, which are time relation and aspectual differences (Gadalla, 2017, pp. 10-11). Here, the translator chooses to change the structure of the source title, by shifting the verb root "يهم" into a noun "أهمية", in a nominal sentence. However, the use of this Arabic grammatical structure does not have a great impact on the consistency of the source message or the coherence of the TT, which is very common in literary texts.

The story starts with an adjacency pair of greeting-greeting sequence between Buzz and Humm. In general, a greeting is an expressive performative act, which reflects the psychological states of the speakers specified in a certain propositional content (Austin, 1962). According to Malinowski (1923; as cited in Nodoushan, 2006, p.3), greetings have "phatic communion" to identify communicative exchanges for contact. In other words, they are types of utterances that generate social bonding functions and express the psychological state in the sincerity condition about the situation regarding the propositional content (Searle, 1979). In Extract 1, the function of greeting is to "maintain a friendly and harmonious atmosphere in interpersonal relations" (Senft, 2014, p.107). The way the two characters greet each other carries implications about their characters (Goffman, 1981, p.128; as cited in Senft, 2014, p.138).

\begin{tabular}{|c|c|c|}
\hline & $\begin{array}{l}\mathbf{S} \\
\mathbf{T}\end{array}$ & TT \\
\hline Extract (1) & $\begin{array}{l}\text { 1. "Greetings, slotted pig," said } \\
\text { Buzz. } \\
\text { 2. "Hello, Buzz," said Hamm } \\
\text { the piggy bank. "How are } \\
\text { you getting used to life here } \\
\text { in Andy's room?" } \\
\text { 3. "Life on this planet is quite } \\
\text { interesting," Buzz said. "I } \\
\text { look forward to giving a full } \\
\text { report to my commander } \\
\text { upon my return tobase." }\end{array}$ & 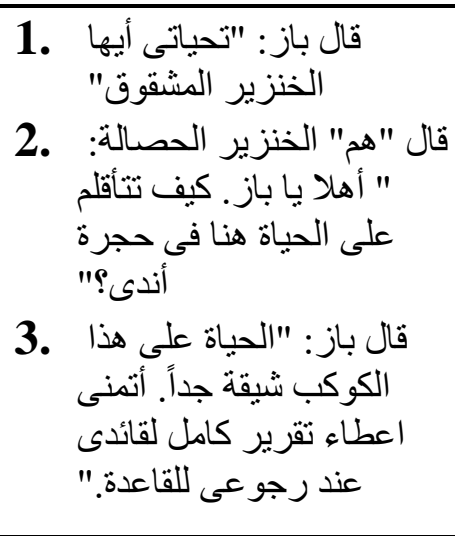 \\
\hline
\end{tabular}

Accordingly, in utterance 1, Buzz uses Halliday's (1979) time-free greeting that strengthens the interpersonal metafunction of the discourse. His greeting reflects Austin's (1962) second-class illocutionary effect which has a conventional effect, as the speaker does not use the normal way but generates an effect. According to Spencer and Pahl (2006; as cited in Clancy, 2016, pp.7-10), the notion of friendship repertoire means that the participants of a conversation are comfortable with dealing with each other. However, the toys are supposed to be friends, Buzz usually 
uses a different kind of language to indicate his uniqueness and usually violates the maxim of approbation.

Correspondingly, in his reply in utterance 2, Hamm attempts to highlight the involvement strategy by using the intimate greeting "Hello" and a direct interrogative about Buzz. The coherence of the text depends heavily on shared background knowledge, in which the reader should be aware of the reason behind such a question. It can be understood in the light of what Baker (2011) discusses how texts can make sense only if "it can be related to other information we already have" (p.255). In Hamm's question "How are you getting used to life here in Andy's room?" he uses a spatial deixis "here" as a cataphoric reference. It indicates the position of both, the speaker, and the hearer "Andy's room", where all the toys are put together. The question implies the fact the speaker knows that this reference "Andy's room" is a new context to the hearer, as pragmatics pays attention to the implied messages and the role of the context in interpreting a given utterance. It may be noted that the speaker flouts the maxim of quantity by using the expression "getting used to life".

On the other hand, the TT implies the same pragmatic analysis using the Arabic language system. In the translation of the characters' names, the translator keeps the same names of the ST, although the Arab children are not aware of some of them. In Extract 1, the analysis of greetings in the TT reflects a major part of "the pragmatic structure". The translator reflects the difference between the two characters by using two different Arabic greetings that are used in different contexts "تحياتى" and" Similarly, the translator succeeds in rending the relationship between the characters in the lexical choices made.

However, the target reader is not familiar with the lexical adjective "مشثقوق" which is used by the translator. It is difficult to comprehend it, yet the reader can guess the meaning from the description of " الحصالة "الخنزير Meanwhile, the choice of a suitable equivalent depends on the linguistic system as well as the "expectations, background knowledge, and prejudices" of the target reader (Baker, 2011, p.15). The translator succeeds in translating the English lexical "bank" in describing the speaker to the correct equivalent in the TL "حصالة". 


\begin{tabular}{|c|c|c|}
\hline \multicolumn{3}{|c|}{ Monica Mouris Naguib } \\
\hline & ST & TT \\
\hline Extract (2) & $\begin{array}{l}\text { 4. Hamm rolled his eyes. } \\
\text { 5. Andy's newest toy was a } \\
\text { little bit bonkers, in his } \\
\text { humble opinion. Buzz had } \\
\text { no idea he was not an } \\
\text { actual space ranger. It } \\
\text { would be funny if it } \\
\text { wasn't so ... annoying. }\end{array}$ & 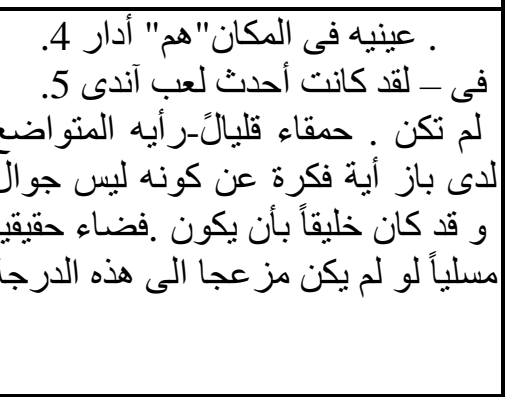 \\
\hline
\end{tabular}

As extract 2 starts with the idiomatic expression "roll (one)'s eyes" which is defined by the Cambridge Dictionary as a movement of the eyes upwards as a way of showing that you are annoyed or bored after someone has done or said something. Following Leech's (1983) politeness principle, Hamm's reaction relies heavily on minimizing the praise of others by uttering nothing. In utterance 4, Hamm commits FTA on record without redressive action (Brown \& Levinson, 1987), threatening the hearer's negative face want. In the TT, the translator does not deal with the idiomatic expression correctly, thus, the implied perlocutionary effect is not reflected. The term "ادار عينيه فى المكان" can simply imply that he is searching for something or looking after something. The writer violates the maxim of quantity by not giving enough information about the speaker's emotions. However, the writer depends heavily on the shared background knowledge he has with the readers to generate more implied messages. Nevertheless, the writer explicitly describes the implied reason behind Hamm's reaction in the writer's comment, in utterance 5. Additionally, the writer puts Hamm thoughts into voiced sentences in the ST, to reflect the reason behind his anger.

Towards the end of utterance 5 in the ST, there are three dots that indicates ellipses. Halliday and Hassan (1976) define ellipsis as the omission of an item in a grammatical structure. However, utterance 5 , it reflects another function, which is hesitation. The speaker is exchanging with the readers his inner thoughts. In other words, writers may use ellipses to show a pause or wavering in an otherwise straightforward thought. The TT follows the same ST system in sentence structure, which is not neutral in writing in the TL. In other words, the translator uses the parenthetical sentence "فى رأيه المتو اضع", however, the translator omits the ellipsis and completes the sentence. Thus, the perlocutionary effect of the source reader differs from that of the target reader. 


\begin{tabular}{|c|c|c|}
\hline & $\begin{array}{l}\mathbf{S} \\
\mathbf{T}\end{array}$ & $\begin{array}{l}\mathbf{T} \\
\mathbf{T}\end{array}$ \\
\hline $\begin{array}{l}\text { Extract } \\
\text { (3) }\end{array}$ & $\begin{array}{l}\text { 6. "So, pig," Buzz continued. } \\
\text { "TodayI noticed Andy placing } \\
\text { several round silvery discs into } \\
\text { the slot onyour back." } \\
\text { 7. "Yes," began Hamm, "that was..." } \\
\text { 8. "And now these silver discs } \\
\text { residein your stomach cavity?" } \\
\text { Buzz interrupted. } \\
\text { 9. "Well, yes," began Hamm, } \\
\text { pattinghis full bell. "But ..." } \\
\text { 10. "Aha!” Buzz cried. "I have } \\
\text { determined your power source! } \\
\text { What an interesting life- form } \\
\text { youare! This will definitely } \\
\text { make it into my report!" }\end{array}$ & 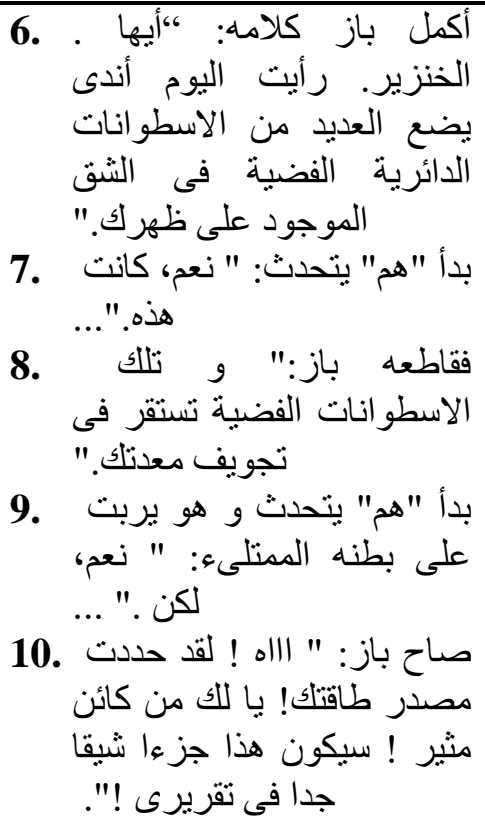 \\
\hline
\end{tabular}

Throughout the conversation in extract 3, the speaker, Buzz, kept asking questions and interrupting the answers, as if he were a real reporter. In utterance 6, regarding Leech's (1983) politeness principle, the speaker violates the maxim of approbation by minimizing praise of others in addressing the hearer without saying his name. Besides, Buzz starts to ask questions, imposing upon the hearer's negative face wants; not to be interrupted and to be respected. Buzz's illocutionary act expresses the speaker's psychological state; hence, the illocutionary force of such an involvement strategy expresses convivial function. Here, in utterances 7 and 9, the ellipsis shifts its function from hesitation to interruption. Correspondingly, this is considered an FTA for the hearer that challenges his independent negative face (Brown \& Levinson, 1987, p.65). While in utterance 10, Buzz's FTA is to Hamm's positive face, as he completely ignores Hamm and concentrates on his report "This will definitely make it into my report!"

In the TT, for the sake of the coherence of the text, the translator adds the object " "كاده" of the verb " coordinate conjunction, the translator changes it to the usage of "أيها", a vocative particle preceding a noun used in direct address. The FTAs done by Buzz in the ST are transferred directly to the TT with its equivalent, by the usage of ellipsis also. Additionally, the translator adds the spoken language signs as "oilip" in utterance 10, and also in utterance 15 (Extract 5 , below), however, "well" in utterance 9 is not translated. 


\begin{tabular}{|c|c|c|}
\hline \multicolumn{3}{|c|}{ Monica Mouris Naguib } \\
\hline & ST & TT \\
\hline Extract (4) & $\begin{array}{l}\text { 11. "What's going on?" Woody } \\
\text { asked. } \\
\text { 12. "Greetings, cowboy," said } \\
\text { Buzz. "Iwas just inquiring } \\
\text { about the pig's power } \\
\text { source." } \\
\text { 13. "He's talking about the } \\
\text { coins inmy belly," Hamm } \\
\text { explained. } \\
\text { 14. "No, Buzz," explained Bo } \\
\text { Peep. "Those aren't power } \\
\text { sources. They're money." }\end{array}$ & 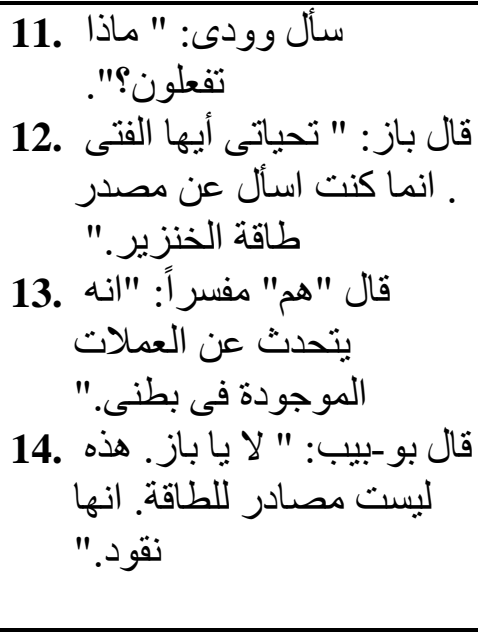 \\
\hline
\end{tabular}

In Extract 4, the third and fourth main characters appear Woody and Bo Peep. In utterance 11, Woody starts with an interrogative to be involved in the conversation. "What's going on?" is one of the questions that can be regarded as Halliday's (1979) time-free greeting. As mentioned in Extract 1, the greeting of Buzz in utterance 12 by the usage of an adjective "cowboy" is marked as a violation of the maxim of politeness. However, due to the fact of being from another planet, Buzz uses a different style. In utterance 13, Hamm attempts to enhance the positive face of Woody by giving more explanation for the wrong answer of Buzz without correcting Buzz's answer. Consequently, Bo Peep, the shepherdess, gets involved in the conversation, violating the maxim of agreement to correct a mistaken interpretation, in utterance 14. On the other hand, in the TT, the translator mainly uses the direct equivalent to the ST. In translating the character's names, the translator uses the same names of the ST "وودى" aبو بيبي" However, due to the lack of the translator's background information about the whole story, Bo Peep is translated as a masculine character. In utterance 9, the reported verb is

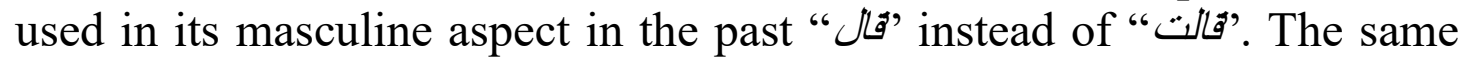
error is done by the translator several times as in utterance 16, below.

The speaker, Woody, follows the modesty maxim by minimizing praise of self by flouting the approbation maxim of minimizing the dispraise of others (utterance 18, below). However, the speaker is not serious in his offensive remark. This is observed in the usage of the adjective (laughed out loud), so the banter principle is aroused reflecting solidarity with the addressees. It can be asserted also in terms of applying Scollon and Scollon's (2001) politeness system of solidarity; that the speaker and the hearer are equal without any recognizable deferential 
distance "Look at us". As they are all groups of toys (-P) and there is no social distance (-D). They all exist in a solidarity system.

\begin{tabular}{|c|c|c|}
\hline & ST & TT \\
\hline $\begin{array}{l}\text { Extract } \\
\text { (5) }\end{array}$ & $\begin{array}{l}\text { 15. Buzz thought for a moment. } \\
\text { "Perhaps I need to procure some } \\
\text { ofthis power source... um, I } \\
\text { mean money, for myself," he } \\
\text { suggested thoughtfully. } \\
\text { 16. "I would get myself a new } \\
\text { staff,"said Bo Peep. "This } \\
\text { one's seen better days." } \\
\text { 17. Woody started daydreaming } \\
\text { aboutwhat he would buy. } \\
\text { 18. But then he looked around and } \\
\text { laughed out loud. "Look at us, } \\
\text { we'rebeing silly!" he said. } \\
\text { 19. "We're toys! Toys can't just } \\
\text { go to the store and walk up to } \\
\text { the counterto buy things!" }\end{array}$ & 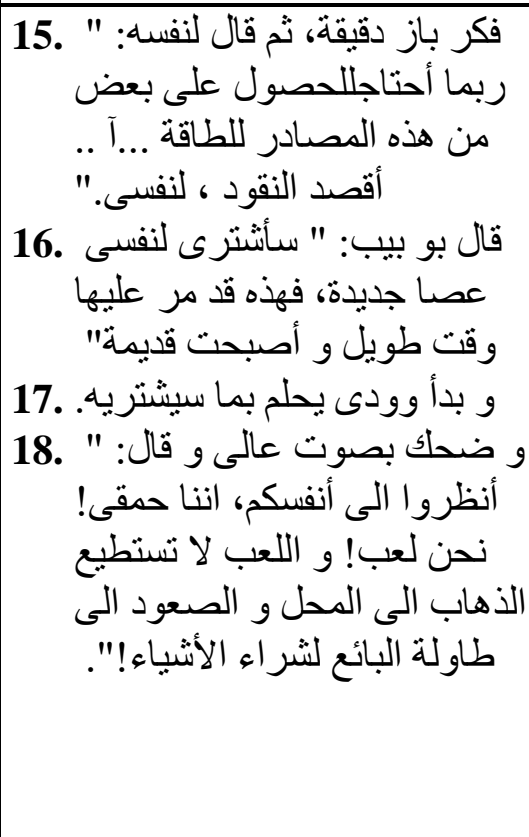 \\
\hline
\end{tabular}

Therefore, the speaker "Woody" is not considered impolite or offensive because of the familiarity and intimacy between the interlocutors (toys). The focus of the intimacy and familiarity is highlighted in Woody's utterance; in other words, it is based primarily on Scollon and Scollon's (2001) strategy of claiming in a group membership with the addressees. There is a collaborative illocution in Woody's announcement "Look at us, we are being Silly! We are toys!". In other words, the speaker makes use of pronouns as (us, we) to emphasize the group relation between the addressees (toys). "We are toys" the assertive illocution manifests that the addresser perceives the maxim of sympathy of "maximizing sympathy between self and other". "Look at us" is not a direct request, however, it is a reminder of their nature. On the other hand, the translator does not reflect the group relation in the usage of pronouns in the first part of utterance 18 " then it is followed by the pronoun "نil' that reduces the power of the deference politeness system. Since there is no power difference between the characters (-P), the translator emphasize the individuality of the speakers.

\subsection{Step 2: On the translation quality assessment level}

\subsubsection{Applying Nord's (1997) translation commission}

Each translation task should be accompanied by a translation commission "that identifies the intended function of the texts and the addressees" (Nord, 1997, p.60). It is considered as the fundamental step during the process of the translation assessment. One of the reasons, as 


\section{Monica Mouris Naguib}

stated by Nida (1964), that there are several motives or combinations of feelings that may affect the translator's work. Hence, a translation commission should be identified first for both the ST and TT profiles. Accordingly, the comparison reveals the differences between the ST and TT profiles, which enable the translator to "prioritize what information to include in the TT" (Munday, 2008, p.83). The deviation is limited to two factors: (a) the addressees and (b) time and place aspects. The importance of such a translation commission is that it helps the translator to concentrate on what information should be included in the TT while making decisions for the translation process. Then, the next step is applying House's (2015) eclectic model to realize the overt and covert errors of the target translation along the Register (Field, Tenor, and Mode) dimensions and genre.

\subsubsection{Applying House's (2015) translation quality assessment model}

The ST profile is presented on the three register dimensions, the field (table 1), the tenor (table 2) and mode (table 3 ) in the following tables.

Table 5.1

ST Profile on the Field dimension

\begin{tabular}{|c|c|}
\hline 1. Subject matter & $\begin{array}{l}\text { The text presents a bedtime short story, which is an } \\
\text { adaptation ofDisney's Toy Story. }\end{array}$ \\
\hline 2. Social Action & $\begin{array}{l}\text { The text highlights simply the usage of money and how } \\
\text { people use it. }\end{array}$ \\
\hline \multicolumn{2}{|r|}{ 3. Features } \\
\hline 3.1 Syntactic means & Examples \\
\hline $\begin{array}{l}\text { - Usage of simple } \\
\text { structures } \\
\text { (i.e. interrogatives) }\end{array}$ & $\begin{array}{l}\text { "How are you getting used to life here in Andy's } \\
\text { room?" ( } c f . \text { Extract 1, utterance } 2) \text {. } \\
\text { "What's going on?" Woody asked. (cf. Extract 4, } \\
\text { utterance 11). }\end{array}$ \\
\hline $\begin{array}{l}\text { Usage of idiomatic } \\
\text { expressions }\end{array}$ & "Hamm rolled his eyes" ( $c f$. Extract 2 , utterance 4$).$ \\
\hline 3.2 Lexical means & Examples \\
\hline $\begin{array}{l}\text { Presence of explicit } \\
\text { language and simple } \\
\text { vocabulary for } \\
\text { children. }\end{array}$ & $\begin{array}{l}\text { - "Buzz had no idea he was not an actual space ranger" } \\
\text { (cf. Extract } \\
\text { 2, utterance 5). }\end{array}$ \\
\hline $\begin{array}{l}\text { Usage of spoken } \\
\text { language signals }\end{array}$ & $\begin{array}{l}\text { - "Hello, Buzz," said Hamm the piggy bank. (cf. Extract } \\
\text { l, } \\
\text { utterance 1) }\end{array}$ \\
\hline
\end{tabular}


A Critical Discourse Analysis of the Representation of Floyd Protests in Three Electronic Newspapers

\begin{tabular}{|c|c|}
\hline $\begin{array}{l}\text { that help in } \\
\text { imagination. }\end{array}$ & $-\quad \begin{array}{l}\text { "Well, yes," began Hamm. (cf. Extract 3, utterance 9) } \\
\text { "Aha!" Buzz cried. (cf. Extract 3, utterance 10) }\end{array}$ \\
\hline$-\quad$ Textual means & \multicolumn{1}{c|}{ Examples } \\
\hline $\begin{array}{l}\text { Conjunctions (such } \\
\text { as: and, but, so, etc.) }\end{array}$ & $\begin{array}{l}- \\
\text { - "So, pig," Buzz continued. (cf. Extract 3, } \\
\text { utterance 6) "Andnow these silver discs reside in } \\
\text { your stomach cavity?" } \\
\text { Buzz interrupted. (cf. Extract 3, utterance 9) }\end{array}$ \\
\hline
\end{tabular}

\section{Table 5.2}

ST Profile on the Tenor Dimension

\begin{tabular}{|l|l|}
\hline $\begin{array}{l}\text { 1. Author's } \\
\text { Temporal, social } \\
\text { and geographical } \\
\text { province }\end{array}$ & $\begin{array}{l}\text { Unmarked concerning the author's regional, social, and temporal } \\
\text { provenance and it is not directed to a special time. Itis written in } \\
\text { colloquial English. }\end{array}$ \\
\begin{tabular}{|l} 
2. Author's personal \\
(Emotional and \\
intellectual) \\
Stance
\end{tabular} & $-\begin{array}{l}\text { There is no evidence of the emotional and intellectual stanceof } \\
\text { the author throughout the text. So, it is considered a neutral } \\
\text { simple text. } \\
\text { The text is aimed to be read or narrated to children. }\end{array}$ \\
\hline
\end{tabular}

\begin{tabular}{|c|c|}
\hline \multicolumn{2}{|r|}{$\begin{array}{l}\text { Featu } \\
\text { res }\end{array}$} \\
\hline a. Syntactic means & Examples \\
\hline $\begin{array}{l}\text { - Common } \\
\text { use of } \\
\text { declaratives }\end{array}$ & $\begin{array}{l}\text { - "I look forward to giving a full report to my commander } \\
\text { - } \quad \text { "Todon my return to base." (cf. Extract 1, utterance 3) } \\
\text { into the slot on your back." (cf. Extract 3, utterance 3) } \\
\text { - "I have determined your power source!" (cf. Extract 3, } \\
\text { utterance 10) }\end{array}$ \\
\hline $\begin{array}{l}\text { - Usage of short } \\
\text { compound sentences. }\end{array}$ & $\begin{array}{l}\text { - } \quad \text { "But then he looked around and laughed out loud." ( } c f \text {. } \\
\text { Extract 5, utterance 18) }\end{array}$ \\
\hline $\begin{array}{l}\text { - Usage of } \\
\text { exclamatory } \\
\text { structures. }\end{array}$ & $\begin{array}{l}\text { - "I have determined your power source! What an } \\
\text { interesting life- form you are! This will definitely makeit } \\
\text { into my report!" ( } c f . \text { Extract } 3 \text {, utterance } 10) \\
\text { - "We're toys!" ( } c f . \text { Extract } 5 \text {, utterance } 19)\end{array}$ \\
\hline b. Lexical means & Examples \\
\hline $\begin{array}{l}\text { - Usage of words and } \\
\text { imperatives with } \\
\text { positive or negative } \\
\text { connotations. }\end{array}$ & $\begin{array}{l}\text { - "Look at us, we're being silly!" he said. ( } c f . \text { Extract 5, } \\
\text { utterance 18) }\end{array}$ \\
\hline c. Textual means & Examples \\
\hline $\begin{array}{lr}\text { - The text } & \text { achieves } \\
\text { strong } & \text { cohesion } \\
\text { through } & \text { the } \\
\text { references } & \text { and }\end{array}$ & $\begin{array}{l}\text { - "How are you getting used to life here in Andy's room?" ( } c f \text {. } \\
\text { Extract 1, utterance 2) } \\
\text { - It would be funny if it wasn't so ... annoying" ( } c f \text {. Extract } 2 \text {, } \\
\text { utterance 5) }\end{array}$ \\
\hline
\end{tabular}




\section{Monica Mouris Naguib}

ellipsis

3. Social role The relationship between the author and reader in the story is relationship symmetrical (marked by the existence of solidarity or equality) and highly personal in the character's dialogues to strengthen the interpersonal metafunction of the whole text.

\begin{tabular}{|c|c|}
\hline \multicolumn{2}{|r|}{ Features } \\
\hline a. Syntactic means & Examples \\
\hline $\begin{array}{l}\text { - Usage of the } \\
\text { narrator'scomments }\end{array}$ & $\begin{array}{l}\text { "Andy's newest toy was a little bit bonkers, in his } \\
\text { humbleopinion. Buzz had no idea he was not an actual space } \\
\text { ranger. It would be funny if it wasn't so ... annoying." ( } c f \text {. } \\
\text { Extract 2, utterance 5). }\end{array}$ \\
\hline b. Lexical means & Examples \\
\hline $\begin{array}{l}\text { - Usage of shared } \\
\text { background } \\
\text { knowledge }\end{array}$ & $\begin{array}{l}\text { - "How are you getting used to life here in Andy's room?" } \\
\text { - "Life on this planet is quite interesting," Buzz said. "I look } \\
\text { forward to giving a full report to my commander upon my } \\
\text { return to base." } \\
\text { (cf. Extract } 1, \text { utterance } 2 \& 3)\end{array}$ \\
\hline 4. Social attitude & $\begin{array}{l}\text { The text is written in colloquial English, used to be } \\
\text { easilycomprehended by children as the target audience. }\end{array}$ \\
\hline & Features \\
\hline a. yntactic means & Examples \\
\hline $\begin{array}{l}\text { - Usage of verbal } \\
\text { nouns and noun } \\
\text { phrases }\end{array}$ & $\begin{array}{l}\text { - "I have determined your power source! What an interesting } \\
\text { life- form you are! This will definitely make it into my } \\
\text { report!" (cf. Extract } 3 \text {, utterance 10) }\end{array}$ \\
\hline b. exical means & Examples \\
\hline $\begin{array}{l}\text { - Usage of } \\
\text { common informal } \\
\text { expressions and } \\
\text { contractions }\end{array}$ & $\begin{array}{ll}\text { - } & \text { "Hello, Buzz," said Hamm the piggy bank. (cf. Extract 1, } \\
& \text { utterance 2) } \\
\text { - } & \text { "Aha!" Buzz cried. (cf. Extract 3, utterance 10) } \\
\text { - } & \text { "He's talking about the coins in my belly," Hamm explained. } \\
\text { (cf. Extract 4, utterance 13) }\end{array}$ \\
\hline
\end{tabular}

Table 4.3

ST Profile on the Mode Dimension

\begin{tabular}{|c|l|}
\hline 1. Medium & $\begin{array}{l}\text { Simple, because the text is written to be read by or } \\
\text { narrated tochildren, as bedtime short story. }\end{array}$ \\
\hline \multicolumn{2}{|c|}{ Features } \\
\hline a. Syntactic means & \multicolumn{1}{c|}{ Examples } \\
\hline - Usage of spoken signals & $-\begin{array}{l}\text { "Hello, Buzz," said Hamm the piggy bank. (cf. } \\
\text { Extract 1, utterance 1) } \\
\text { "Well, yes," began Hamm. (cf. Extract 3, utterance } \\
\text { 9) } \\
\text { "Aha!" Buzz cried. (cf. Extract 3, utterance 10) }\end{array}$ \\
\hline b. Lexical means & \multicolumn{1}{c}{ Examples } \\
\hline
\end{tabular}


A Critical Discourse Analysis of the Representation of Floyd Protests in Three Electronic Newspapers

- Usage of explicit simple phrasal verbs used in written forms.
- "We're toys! Toys can't just go to the store and walk up tothe counter to buy things!" (cf. Extract 6, utterance 19)

\section{c. Textual means \\ - $\quad$ Usage of direct questions}

2.

2. Participants

Simple. It can be defined as a monologue as the addresseesare not participating in the next with the author.

On the other hand, the Genre of the text belongs to children's literary discourse. It is a bedtimeshort story from a Disney book designed for the Arab world's children, usually read by adults. The first and main communicative purpose is to entertain children by recreating short events by the famous Disney characters in 365 short stories. This is illustrated in Nord's (1997) motive aspect of the translation commission.

The statement of function of this story includes both ideational and interpersonal metafunctions. The ideational is mainly asserted due to the Genre dimension of the text and that it takes a place in the children's literature. The interpersonal metafunction is vivid in the intention of the author to provoke thoughts and to be informed correctly and to call for action on behalf of the target readers. The two functions are observed by the same degree of occurrence, yet the ideational metafunction still stands slightly higher. On the Field dimension, the usage of the interrogative and intimate discourse as well as the frequent use of spoken language signals the interpersonal metafunction. On the Tenor dimension, the author's personal stance is un-marked; there is no emotional or intellectual interference through the ST. The repeated use of the declarative sentences, and the lack of foregrounded structures that generate emotive effects, contribute to both the interpersonal and ideational functions. While on the Mode dimension, the usage of the verbal signals proves that the medium is simple, written to be read but as if heard.

The researcher produces the same analysis along with House's (2015) model on the TT to conduct a statement of quality. The statement of quality of the analysis of both the ST and TT textual profiles highlights that either the ideational function or the interpersonal function of the text has been affected in the translation to a certain extent. In other words, in the Arabic translation, the ideational metafunction is less strongly marked. The translator consciously uses a cultural filter and changes the English text accordingly. The analyses and comparison of the two profiles 


\section{Monica Mouris Naguib}

show the lingua-differences along the dimensions. Lexical, syntactic, and textual differences are observed in which they affect both the interpersonal and ideational functions of the text. However, the perlocutionary effect of the two texts is similar. Both texts are characterized as expressing their meaning directly. The translator leans on the TL's system to convince the addressees of the value of the text. In addition, the diversion of the ST structures supports the target readers to feel it as if it were written in their language, the Arabic Language.

On the other hand, as it has been seen in the statement of function above, the interpersonal metafunction is more significant than the ideational one. In the TT, the interpersonal metafunction is affected by two elements: (a) the use of less expressive structures, and (b) the lack of the spoken language indicators. Regarding the structures, there are few instances where the lexical choices reflect a more neutral stance in the TL system for the target readers. Since the statement of function implies that both ST and TT have equivalent purposes for comparable audiences, thus, a covert translation is conducted. Consequently, the cultural filter is applied to produce a text that is like the ST.

\section{Conclusions}

In conclusion, through the pragmatic analysis along with the functional translation models on the selected extracts, the results show that the translator prefers to tie the TT with the regulations of the TL, communitywise and cultural wise. The translator concentrates on the target readers to have a readable, adequate, and coherent TT. To conduct this, it is recognized that the ST and TT functions are kept equivalent, as they are having the same purposes, which is to enhance the children's literature addressing certain age. Therefore, this translated text tends to have a covert translation than an overt one.

The statement of quality reveals that the TT strongly follows a covert translation. Cultural references, discourse, and register are completely appropriate for the TL system and are presented in a simple discourse that suits the target audiences, i.e. children. In her book, Lathey (2010) states that a "degree of stylistic and semantic creativity is essential to a successful translation of texts for adults or children" (p.6). Although the translator makes every effort to code and decode the implicit information illustrated in the pragmatic analysis above, the differences between the two profiles are acceptable. 


\section{Table 6.1}

Types of Overt Errors that occur in the Story

\begin{tabular}{|c|c|c|c|}
\hline $\begin{array}{l}\text { Types of } \\
\text { errors }\end{array}$ & ST & TT & Comments \\
\hline $\begin{array}{l}\text { 1. Slight } \\
\text { change in } \\
\text { Meaning }\end{array}$ & $\begin{array}{l}\text { - "I look forward } \\
\text { to giving a full } \\
\text { report to my } \\
\text { commander" }\end{array}$ & 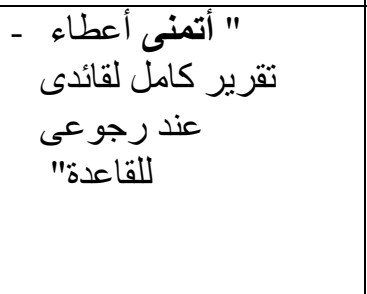 & $\begin{array}{l}\text { The translator in the } \\
\text { first utterance hasmade } \\
\text { a slight difference in } \\
\text { meaning, that can be } \\
\text { translated in the TT as } \\
\text { "أنطل" not hoping. }\end{array}$ \\
\hline $\begin{array}{l}\text { 2. } \\
\text { Significa } \\
\text { nce } \\
\text { change }\end{array}$ & $\begin{array}{l}\text { "No, Buzz," } \\
\text { explained Bo } \\
\text { Peep. }\end{array}$ & قال بو بيب: "لا باز - & $\begin{array}{l}\text { The translator is not } \\
\text { aware that Bo Peep is a } \\
\text { female character } \\
\text { should be reflected in } \\
\text { the reported verb قالت }\end{array}$ \\
\hline Distortion & $\begin{array}{l}\text { - "Ham rolled } \\
\text { his eyes" }\end{array}$ & 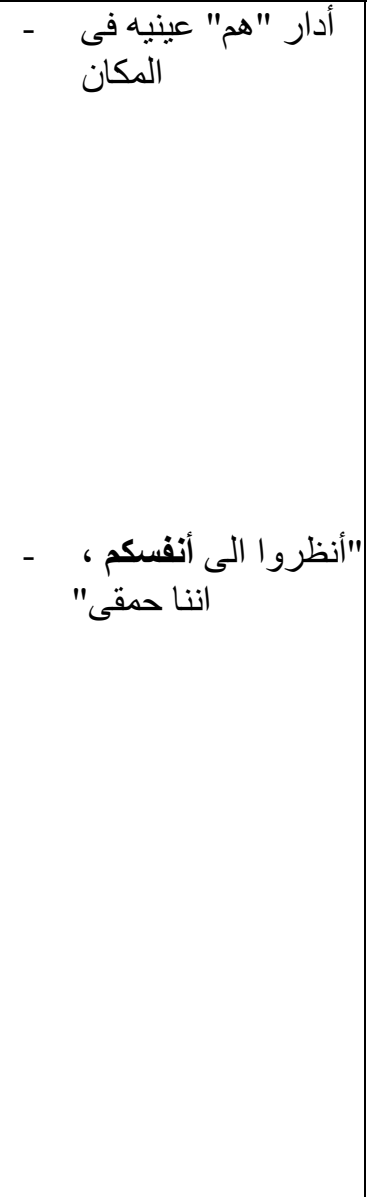 & 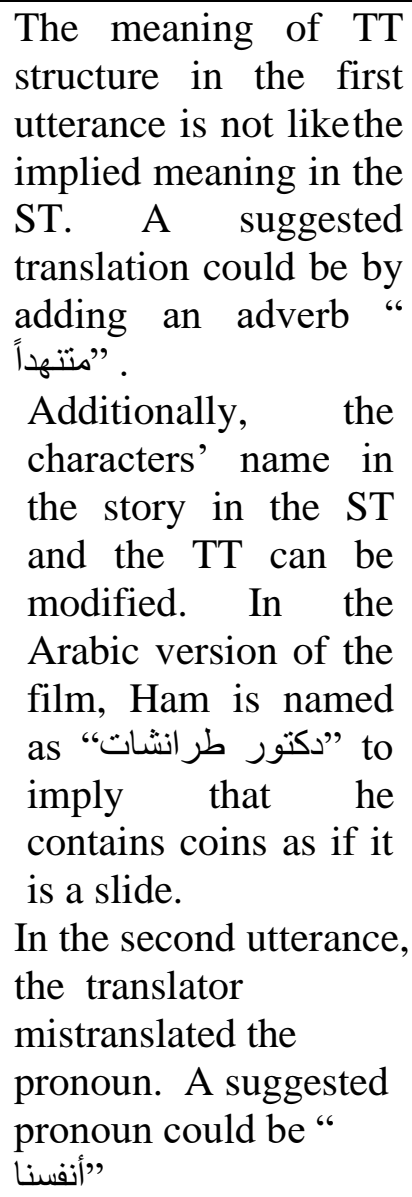 \\
\hline
\end{tabular}

In conclusion, the results of the analysis of the data in the present study, answers the research questions that represent the main objective of the study. The study attempts mainly to answer three major questions investigated through the assessment of three selected short stories for analysis. As for the first question, how can the pragma-stylistic analysis of the selected data uncover the author's intended messages? The detailed analysis proves that the process of analyzing the bedtime 


\section{Monica Mouris Naguib}

stories linguistically benefits the translator of children texts as it provides him/her with a comprehensive translation brief that includes all the information needed to produce a functionally coherent target text.

Concerning the second question, how far does the pragmatic analysis help the scholars of translation to assess the translation of children's literature? The analysis shows that translation of Arabic humorous texts is a problematic one; besides, the translation analysis presents how translators can solve these problems through applying functional translation theories. Furthermore, the detailed analysis of the data presented in this study answer the third question, to what extend is the proposed model capable of assessing the translation quality of the TT? as follows: (a) Comparison between ST and TT addresses leads to the difference in the cultural knowledge that may require an adjustment of the relationship between explicit and implicit information in the text, (b) The motive for the text production is the same for the ST and TT, which is mainly informative over the appellative function, (c) Cultural translation problems can be the result of the differences in the norms and conventions guiding verbal and non-verbal behavior and (d) 7. The functional translation process should start on the pragmatic level by deciding on the intended function of the translation. 


\section{References}

Almanna, A. (2016). The Routledge course in translation annotation: ArabicEnglish-Arabic. London, New York: Routledge.

Austin, J. L. (1962). How to do things with words. Oxford: Clarendon.

Baker, M. (2011). In other words: A course book on translation ( $2^{\text {nd }}$ ed.). London:Routledge.

Black, E. (2006). Pragmatic Stylistics. Edinburgh: Edinburgh University.

Brown, G., \& Yule, G. (1983). Discourse analysis. Cambridge, England: CambridgeUniversity.

Brown, P., \& Levinson, S. (1987). Politeness: Some universals in language use. Cambridge: Cambridge.

Carston, R. (2002). Thoughts and utterances: The pragmatics of explicit communication. Blackwell: Blackwell Publishing.

Clancy, B. (2016). Investigating intimate discourse: Exploring the spoken interaction offamilies, couples and friends. London \& New York: Rutledge.

Crystal, D. (2008). A Dictionary of linguistics and phonetics $\left(6^{\text {th }}\right.$ ed.). London: Blackwell.Retrieved from https://www.pdfdrive.com/a-dictionary-of-linguisticsphonetics- david-crystal-6th-edition-e7077016.html

Disney Enterprises, Inc. (2014). 365 Bedtime stories (6 ${ }^{\text {th }}$ ed.). Cairo: Nahdit Masr.

Emery, P. G. (2004). Translation, Equivalence and Fidelity Dialogue in Arabic to English. Babel, 50 (2), 143-167.

Farghal, M. (2012). Advanced Issues in Arabic- English Translation Studies. Kuwait:Kuwait University.

Farghal, M., \& Almanna, A. (2015). Contextualizing translation studies: Aspects of ArabicEnglish interlingual translation. Cambridge: Cambridge Scholars.

Gadalla, H. A. H. (2017). Translating tenses in Arabic-English and English-Arabic contexts. UK: Cambridge Scholars Publishing.

Goffman, E. (1981). Forms of talk. Oxford, UK: Basil Blackwell.

Green, G. M. (1996). Pragmatics and natural language understanding ( $\left.2^{\text {nd }} \mathrm{ed}.\right)$. NewJersey: Lawrence Erlbaum.

Grice, H. P. (1975). Logic and Conversation. In P. Cole, \& J. L. Morgan (Eds.), Syntaxand Semantics. Speech Acts (pp. 41-58). New York: Academic.

Grice, H.P. (1989). Studies in the way of words. Cambridge, Ma: Harvard University.

Hall, M. F. (2008). Discourse analysis of fictional dialogue in Arabic to English translation. Unpublished PhD thesis. London: University of London.

Halliday, M. A. K. (1979). Differences between spoken and written language: Some implications for literacy teaching. In G. Page, J. Elkins, \& B. O'Conner (Eds.) Communication Through Reading: Proceedings of the Fourth Australian Reading Conference. Adelaidd, (pp. 37-52). S.A.: Australian Reading Association, Longman

Halliday, M. A. K., \& Hasan, R. (1976). Cohesion in English. London, New York: Routledge

House, J. (1977). A model for translation Quality Assessment. Tubingen: Gunter Narr.

House, J. (1997). Translation quality assessment: A model revisted. Tubingen: GunterNarr. 


\section{Monica Mouris Naguib}

House, J. (2015). Translation quality assessment: past and present. London: Routledge.

Lahlali, E., \& Hatab, W. A. (2014). Advanced English-Arabic translation: A practicalguide. Edinburgh: Edinburgh University.

Lakoff, R. T. (1990). Talking power. New York: Basic Books.

Lathey, G. (Ed.) (2006). The translation of children's literature: $A$ reader $\left(2^{\text {nd }}\right.$ ed.). Cleveland, Buffalo, Toronto: Multilingual Matters Ltd.

Lathey, G. (2010). The role of translators in children's literature: Invisible storytellers. London, New York: Routledge.

Leech, G. (1983). Principles of pragmatics. London: Longman.

Levinson, S. (1983). Pragmatics. Cambridge: Cambridge University.

Malinowski, B. (1923). The problem of meaning in primitive languages. In C. K. Ogden \& I.A. Richards (Eds.), The meaning of meaning: A study of the influence of language upon thought and of the science of symbolism (pp. 296336). London: Kegan Paul, Trench \& Trubner.

Mey, J. L. (1993). Pragmatics: An Introduction. Oxford, UK: Blackwell.

Munday, J. (2001). Introducing translation studies: Theories and applications. London, New York: Routledge.

Munday, J. (2008). Style and ideology in translation: Latin American writing in English. New York: Routledge.

Muntigl, P., \& Horvath, A. (2005). Language, psychotherapy and client change: An interdisciplinary perspective. In P. Chilton, \& R. Wodak (Eds.), A new agenda incritical discourse analysis (pp. 213-239). Amsterdam: Benjamins

Neale, S. (1992). Paul Grice and the philosophy of language. Linguistics and Philosophy, 15, 509-559. Retrieved October, 2017, from https://www.academia.edu/2770396/Paul_Grice_and_the_philosophy_of_langua ge

Newbert, A. (1985). Text and translation. Leipzig: Enzyklopadie.

Newmark, P. (1981). Approaches to translation. Oxford, New York: Pergamon.

Nida, E. A. (1964). Towards a science of translating. Leiden: E. J. Brill.

Nodoushan, M. (2006). The socio-pragmatics of greeting forms in English and Persia. Journal of Language, Society and Culture, 17.

Nord, C. (1991/2005). Text analysis in translation: Theory, methodology, and didactic application of a model for translation-oriented text analysis. Amsterdam, New York: Rodopi.

Nord, C. (1997). Translating as a purposeful activity: Functionalist approaches explained. Manchester UK, Kinderhook (NY), USA: St. Jerome.

Nord, C. (2006). Translating for communicative purposes across culture boundaries. Journal of Translation Studies, 9 (1) 51-60.

Oittinen, R. (2000). Translating for children. New York: Garland.

Pan, Y. (2006). Politeness in Chinese face- to- face interaction. Advances in DiscourseProcesses, 67, 303-306. https://doi.org/10.1017/S0047404502272188

Pascua, I. (2006). Translating Cultural References: The Language of Young People in Literary Texts. In van Coillie, J. and W.P. Verschueren (Eds.), Children's literature in translation: Challenges and strategies (pp. 111-121). Manchester: St. Jerome.

Reiss, K., \& H. J. Vermeer. (1984). Grundlegung einer allgemeinen translationstheorie [Foundation of a general translation theory]. Tubingen: Niemeyer. 
Scollon, R., \& Scollon, S. (2001). Intercultural communication: A discourse approach ( $2^{\text {nd }}$ ed.). Oxford: Blackwell.

Scriven, M. (2007). The logic of evaluation. Retrieved from http://scholar.uwindsor.ca/cgi/viewcontent.cgi?article=1390\&context=ossaarchive

Searle, J. R. (1969). Speech acts: An essay in the philosophy of language. Cambridge: Cambridge University.

Searle, J. R. (1976). A taxonomy of illocutionary acts. Language in Society, 5, 125. Cambridge: Cambridge University.

Searle, J. R. (1979). Expressions and meaning: Studies in the theory of speech acts. Cambridge: Cambridge University.

Senft, G. (2014). Understanding pragmatics. London, New York: Routledge.

Spencer, L., \& Pahl, R. E. (2006). Rethinking friendship: Hidden solidarities today. Princeton: Princeton University.

van Coillie, J. (2006). Character names in translation: A functional approach. In J. van Coillie, \& W. P. Verschueren (Eds.), Children's literature in translation: Challenges and strategies (pp. 123-140). London, New York: Routledge.

Williams, M. (2009). Translation Quality Assessment. Ottawa: University of Ottawa.

Yule, G. (1996a). Pragmatics. Oxford: Oxford University.

Yule, G. (1996b). The study of language. Cambridge: Cambridge University.

Zohar, S. (1986). The Poetics of children literature. Athens, GA: University of Georgia. 